\title{
Earing Prediction of Unidirectionally and Cross-rolled, Annealed AW-5056 Al Sheets from \{h00\} Pole Figures
}

\author{
Bence SCHWEITZER, ${ }^{1}$ Márton BENKE, ${ }^{2}$ Adrienn HLAVACS, ${ }^{3}$ Valéria MERTINGER ${ }^{4}$ \\ Institution of Physical Metallurgy, Metalforming and Nanotechnology (University of Miskolc, Faculty of \\ Materials Science and Engineering), Miskolc, Hungary, \\ 1 thebencyx@gmail.com \\ 2 fembenke@uni-miskolc.hu \\ 3femhadri@uni-miskolc.hu \\ ${ }^{4}$ femvali@uni-miskolc.hu
}

\begin{abstract}
Earing of deep drawn cups is an effective measure of plastic anisotropy. It is the result of crystallographic anisotropy, i.e. texture. There are several methods to predict earing, but all of these methods are rather complex. Furthermore, above a certain sheet thickness, deep drawing cannot be performed, and prediction methods fail since they are usually valid within a certain sheet thickness range. A new, simple method has been proposed to predict earing. Besides simplicity, another major benefit of the method is that it can be applied to a wide range of sheet thicknesses. The method has been previously applied for unidirectionally rolled and recrystallized and cross-rolled $\mathrm{Al}$ sheets. In the present manuscript, the proposed method is applied on the AW-5056 type, unidirectionally and cross-rolled, then annealed Al sheets having very weak (close to random) structure. It is shown that for such samples, the method predicts negligible earing. It is also revealed that for the 5056 type $\mathrm{Al}$ alloy, the differences in texture and earing between unidirectionally and cross-rolled samples become so small after annealing, that the benefit of cross rolling is negligible.
\end{abstract}

Keywords: cross-rolling, earing, texture.

\section{Introduction}

The term "cross-rolling” is used for several special types of rolling [1]. In this manuscript, cross-rolling refers to a modified version of conventional "unidirectional rolling” during which the sheets are rotated by $90^{\circ}$ about the normal direction (ND) between consecutive passes [2-5]. The result of such a process is a more random texture compared to unidirectional rolling with four-fold symmetry. Li et al. obtained a higher orientation scatter on the rolling plane of Mg sheets [2]. Wronski et al. applied cross-rolling to low carbon steel and copper and established that the anisotropy of plastic formability decreased in copper but increased in the steel [3]. Huh et al. achieved the suppression of cube texture formation in 5182 type Al sheets which resulted in better formability [4]. Tang et al. reported that on cross-rolled
AZ31 type magnesium sheets, negligible earing and increased ductility were obtained [5]. It can be concluded that in general, using cross-rolling, a more random texture and consequently, a more uniform plastic formability can be achieved.

Deep drawing is a simple method to characterize the plastic anisotropy of rolled sheets. Besides this, several methods have been developed to predict earing. Fukui and Kudo showed that earing can be predicted from the Lankford number: $\Delta r=\left(r_{0}+r_{90}\right) / 2-r_{45}$ [6]. Since then, reports have been published about mechanics based [7], crystallography based [8, 9] and more sophisticated methods [10]. Nowadays, earing is usually estimated with finite element (FE) methods [11]. One drawback of the above prediction methods is that they are valid within given sheet thickness ranges. If sheet thickness is out of this range, the mod- 
el must be modified and validated. This becomes crucial if such sheet thickness is the target, where deep drawing cannot be carried out, thus, the method cannot be validated. A simple method has been published recently by the authors which is able to predict earing from $\{\mathrm{h} 00\}$ pole figures [12, 13]. Besides simplicity, the developed method can be applied in a wide sheet thickness range, which makes it a generally applicable method. Furthermore, it can be used on pole figures obtained by EBSD, or by non-destructive (sample-cutting-free) texture measurement methods [14]. The method was successfully applied on unidirectionally cold rolled and subsequently annealed $\mathrm{Al}$ sheets showing the following four-fold earing types: rolling, close to zero and recrystallized earing, at notably different sheet thicknesses $(0,3-3 \mathrm{~mm})$ [12]. ]. Later, it was applied on cross-rolled $\mathrm{Al}$ sheets as well [13]. The present manuscript aims to further widen the applicability of the developed earing prediction method. Now, the method is to be applied on unidirectionally (UD) and cross-rolled (CR) Al sheets which have been subsequently subjected to annealing heat treatments to obtain weak (almost random) recrystallization textures.

\section{Materials and Methods}

Sheets of 5056 aluminum with initial thickness of $4 \mathrm{~mm}$ were unidirectionally- (UD) and crossrolled (CR) using a VonRoll roll stand. Except for the type of rolling (UD or CR), the applied parameters were similar. Sheets were produced with both 6 and 12 passes. Samples A1, A5, and A6 were UD rolled, while samples $\mathrm{A} 3 \mathrm{~K}, \mathrm{~A} 4 \mathrm{~K}$, and $\mathrm{A} 9 \mathrm{~K}$ were $\mathrm{CR}$ rolled to $\sim 1 \mathrm{~mm}$ in 6 passes. Between consecutive passes, sample A4K was rotated around ND clockwise, while samples A3K and A9K were rotated back and forth. The height reduction of the first pass was $0.6 \mathrm{~mm}$, and $0.5 \mathrm{~mm}$ for the subsequent passes. Sample A10 was UD rolled and sample A11K was CR rolled to $1 \mathrm{~mm}$ in 12 passes. The height reduction for the first pass was $0.3 \mathrm{~mm}$ and 0.25 for the following passes. Sample A11K was also rotated back and forth around ND [13]. The rolled sheets were heat treated in an air atmosphere furnace at $320^{\circ} \mathrm{C}$ for 2 hours to obtain a fully recrystallized structure.

Round samples with $30 \mathrm{~mm}$ diameter were cut out from the sheets for X-ray diffraction texture measurements. Texture examinations were carried out using a Bruker D8 Advance X-ray diffractometer with $\mathrm{Cu}$ X-ray source equipped with an Eulerian cradle. The applied tube voltage and current were $40 \mathrm{kV}$ and $40 \mathrm{~mA} .\{111\},\{200\}$, and $\{220\}$ pole figures were measured up to $75^{\circ}$ tilting. Recalculated $\{200\}$ pole figures were obtained with the software of the equipment, TexEval. Orthotropic deformation was applied for the recalculation of both UD and CR samples.

The used earing prediction method is described in detail in a previous publication [12]. In brief, the CHI-cuts of the recalculated $\{200\}$ pole figures were obtained. The $\{200\} \mathrm{CHI}-\mathrm{cuts}$ were plotted for each PHI (sample rotation) angle. The method supposes that the intensity variation on the CHI-cuts can be approximated with a sum of Gaussian curves [15]. The CHI-cuts were fitted with Gaussian curves. The net intensity (area) of each Gaussian curve was determined and weighted (multiplied) with the sine of the CHI values of the peaks of the Gaussian curves. Then, the weighted areas were summed to the given PHI angle. The summarized, weighted $\{200\}$ intensity function versus PHI is the predicted relative cup height variation versus PHI. Predicted average earing was calculated as the ratio of average predicted ear height and average predicted cup height and divided by a scaling factor [12]. The determination of the scaling factor was based on comparison to experimental data described in detail in [13]. The scaling factors for UD and CR cases were 40 and 60 , respectively.

\section{Results}

\subsection{Results of 6 Pass Rolling}

Figure 1 shows the recalculated $\{200\}$ pole figures of the annealed UD and CR samples rolled in 6 passes. On the pole figures, no intensity peaks are present. The RD is at 12'o clock in every case. Thus, it can be said that all the UD and CR samples show a close to random structure.

In Figure 2 the predicted earing and predicted average earing of the annealed samples rolled in 6 passes are summarized. It can be seen that for all UD and CR samples, notable ears that are characteristic to rolling earing at $\mathrm{RD}+45^{\circ}+$ $\left(\mathrm{n} \cdot 90^{\circ}\right)$ directions or ears typical to recrystallized earing at $\mathrm{RD}+\left(\mathrm{n} \cdot 90^{\circ}\right)$ directions (or any other directions) do not appear. The observed differences in cup height are very small, the intensity varies between 60 and 80 counts. Such differences are negligible. This is proved by the predicted average earing which is below 1 . Thus, it can be said that all UD and CR samples show very weak earing. 


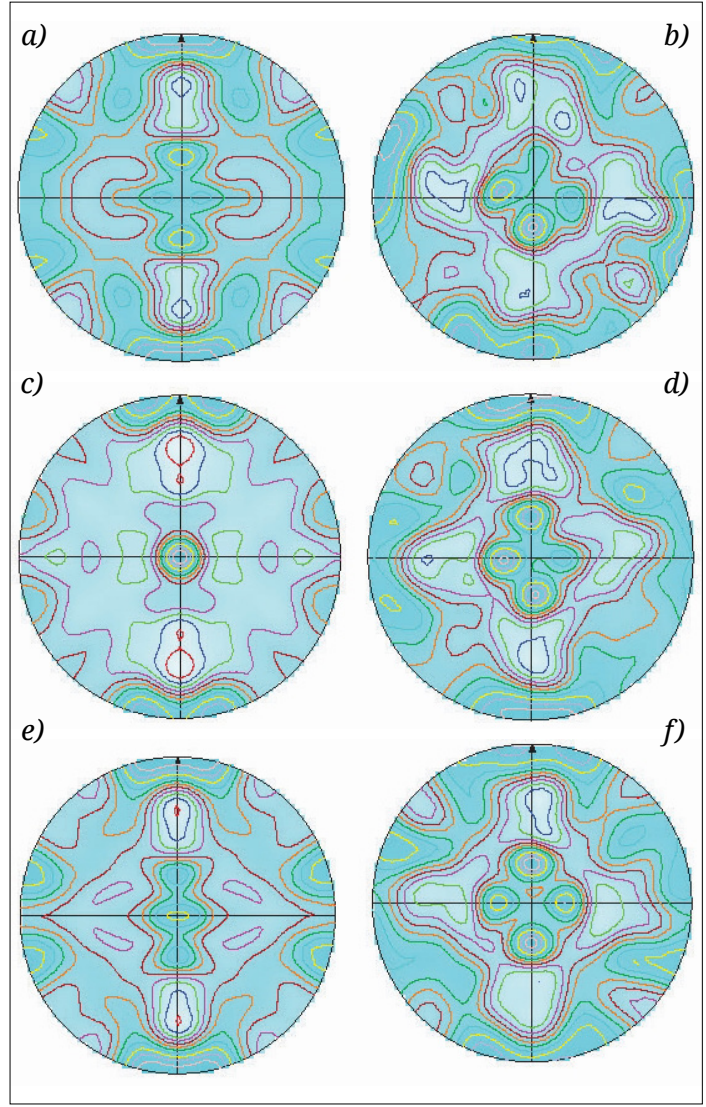

Figure 1. Recalculated $\{200\}$ pole figures of the annealed samples rolled in 6 steps. (a) A1; (b) A3K; (c) A5; (d) A4K; (e) A6; (f) A9K.

\subsection{Results of 12 Pass Rolling}

In Figure 3 the recalculated $\{200\}$ pole figures of the annealed UD and CR samples rolled in 12 passes is presented. It is evident that the annealing heat treatment resulted a random structure in both UD and CR samples.

Figure 4 shows predicted earing and predicted average earing of the samples rolled in 12 passes. According to the figure, both UD and CR samples show weak earing. The predicted average earing is below 1 .

\section{Conclusions}

It was seen that no intensity peaks appeared on the $\{200\}$ pole figures of UD and CR rolled and subsequently annealed AW-5056 type Al sheets. Thus, a homogenous intensity distribution was present on the $\{200\}$ pole figures (i.e., the rolling plane) of the examined samples. The developed earing prediction method is based on the intensity distribution of the $\{\mathrm{h} 00\}$ pole figures i.e., the $\{$ h00\} intensity distribution on the rolling plane. It is shown that in such cases, when a homogenous $\{200\}$ intensity distribution is present on the rolling plane, very small cup height variations and weak average earing is obtained using the developed earing prediction method. It is also shown that for the AW-5056 type $\mathrm{Al}$ alloy, the differences in texture and earing between UD and CR samples become so small after annealing, that the benefit of cross rolling is negligible.

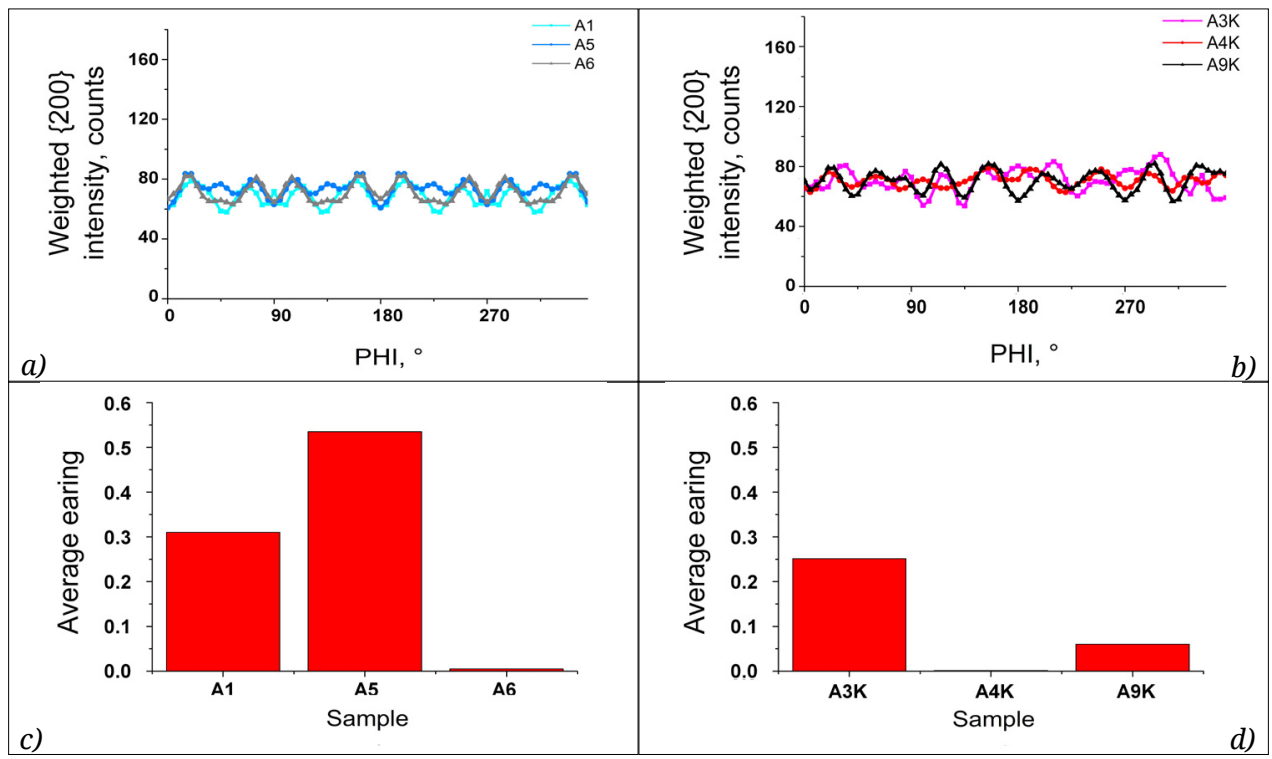

Figure 2. Predicted earing of the annealed samples rolled in 6 steps. (a) UD samples; (b) CR samples; (c) predicted average earing of the UD samples, (d) CR samples. 


\section{Acknowledgment}

The described article was carried out as part of the EFOP-3.6.1-16-2016-00011 "Younger and Renewing University - Innovative Knowledge City - institutional development of the University of Miskolc aiming at intelligent specialization” project implemented in the framework of the Szechenyi 2020 program. The realization of this project is supported by the European Union, co-financed by the European Social Fund. Supported by the ÚNKP-19-4 New National Excellence Program of the Ministry for Innovation and Technology and the NKFIH K119566 project.

\section{References}

[1] Neugebauer R., Glass R., Kolbe M., Hoffmann M.: Optimisation of processing routes for cross rolling and spin extrusion. J. Mater. Process. Tech. 125126. (2002) 856-862.

https://doi.org/10.1016/S0924-0136(02)00392-8

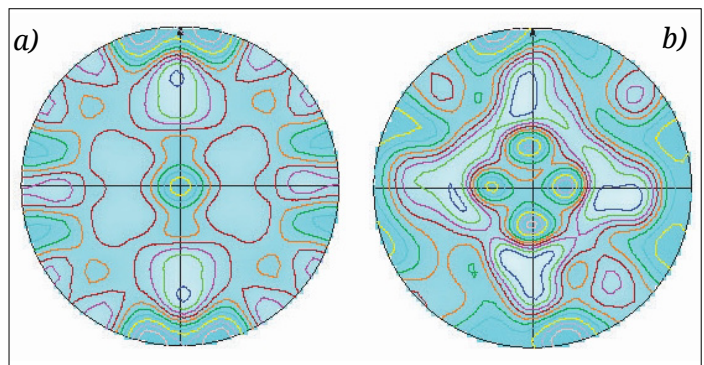

Figure 3. Recalculated $\{200\}$ pole figures of the annealed samples rolled in 12 steps. (a) A10; (b) $A 11 K$.
[2] Li X., Al-Samman T.: Mechanical properties and anisotropy of ME20 magnesium sheet produced by unidirectional and cross rolling. Materials \& Design 32. (2011) 4385-4393.

https://doi.org/10.1016/j.matdes.2011.03.079

[3] Wronski S., Wrobel M., Baczmanski A., Wierzbanowski K.: Effects of cross-rolling on residual stress, texture and plastic anisotropy in f.c.c. and b.c.c. metals. Materials Characterization 77. (2013) 116-126.

https://doi.org/10.1016/j.matchar.2013.01.005

[4] Huh M. Y., Cho S. Y., Engler O.: Randomization of the annealing texture in aluminum 5182 sheet by cross-rolling. Materials Science and Engineering A, A315. (2001) 35-46.

https://doi.org/10.1016/S0921-5093(01)01207-2

[5] Tang W., Huang S., Li D., Peng, Y.: Mechanical anisotropy and deep drawing behaviors of AZ31 magnesium alloy sheets produced by unidirectional and cross rolling. Journal of Materials Processing Technology, 215. (2015) 320-326.

https://doi.org/10.1016/j.jmatprotec.2014.08.020

[6] Fukui S., Kudo H.: The earing in deep-drawing and directionality in tension-test of sheet metal. Rep. Inst. Sci. Tech. Univ. Tokyo, 4 (1950) 33.

[7] Sowerby R., Johnson W.: Prediction of earing in cups drawn from Anisotropic sheet using slip-line field theory. Journal of Strain Analysis for Engineering Design, 9 (1974) 102-108. https://doi.org/10.1243\%2F03093247V092102

[8] Tucker G. E. G.: Texture and earing in deep drawing of aluminium. Acta Metallurgica, 9 (1961) 275-286.

https://doi.org/10.1016/0001-6160(61)90220-6

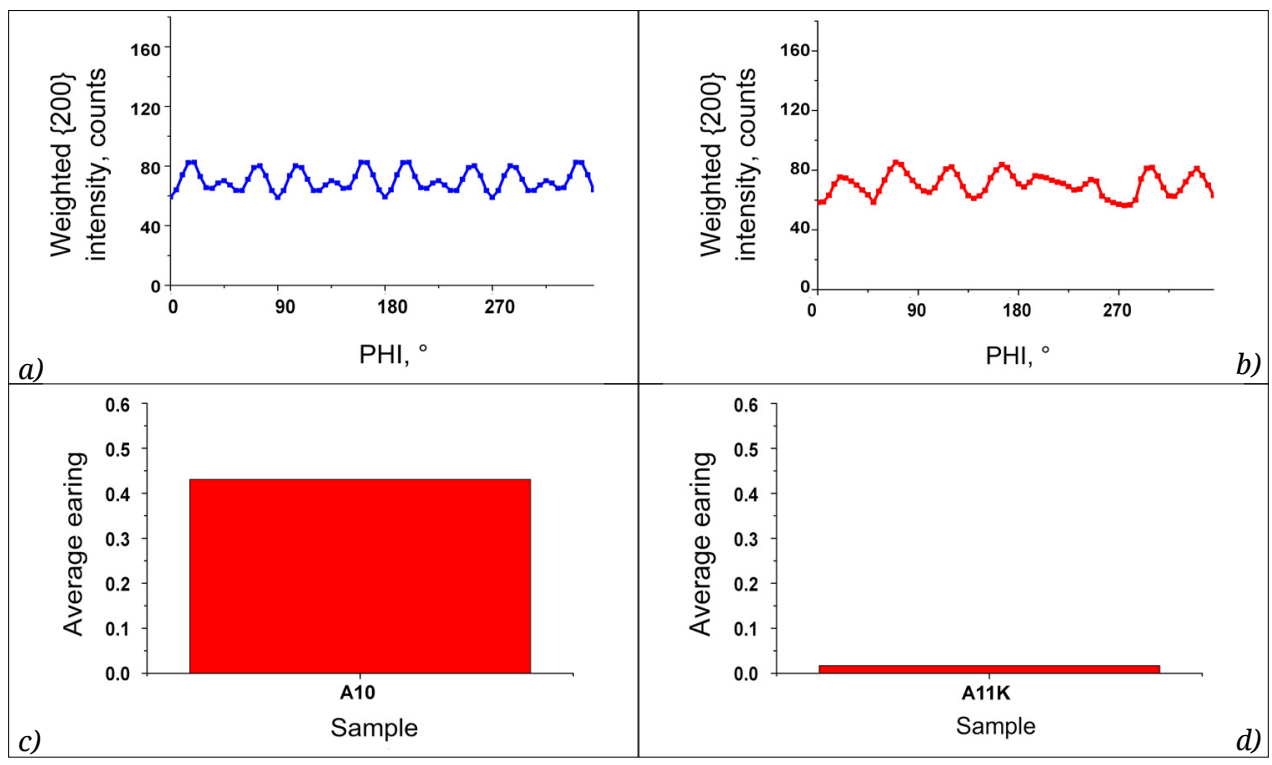

Figure 4. Predicted earing of the annealed samples rolled in 12 steps. (a) UD sample; (b) CR sample; (c) predicted average earing of the UD sample, (d) CR sample. 
[9] Kanatake N., Tozawa Y., Otani T.: Calculations from texture of earing in deep drawing for fcc metal sheets. International Journal of Mechanical Sciences, 25. (1983) 337-345.

https://doi.org/10.1016/0020-7403(83)90012-7

[10] Van Houtte P., Cauwenberg G., Aernoudt E.: Analysis of the earing behaviour of aluminium 3004 alloys by means of a simple model based on yield loci calculated from orientation distribution functions. Materials Science and Engineering, 95. (1987) 115-124.

https://doi.org/10.1016/0025-5416(87)90503-9

[11] Engler O., Mertens N., Van Dam P.: Texture-based design of a convoluted cut-edge for earing-free beverage cans. Journal of Materials Processing Technology, 211. (2011) 1278-1284.

https://doi.org/10.1016/j.jmatprotec.2011.02.011
[12] Benke M., Hlavacs A., Imre P., Mertinger V.: Prediction of earing of aluminium sheets from $\{h 00\}$ pole figures. European Journal of Mechanics endash; A/Solids, 81. (2020) 103950.

https://doi.org/10.1016/j.euromechsol.2020.103950

[13] Benke M., Schweitzer B., Hlavacs A., Mertinger V.: Prediction of earing of cross-rolled Al sheets from $\{$ h00\} pole figures. Metals - Open Access Metallurgy Journal, 10/2. (2020) 192. https://doi.org/10.3390/met10020192

[14] Sepsi M., Mertinger V., Benke M.: Sample cutting-free pole figure measurement method for centreless diffractometers in modified $X$ mode. Materials Characterization, 151. (2019) 351-357. https://doi.org/10.1016/j.matchar.2019.03.031

[15] Ma Q., Mao W., Feng H., Yu Y.: Rapid texture measurement of cold-rolled aluminum sheet by $X$-ray diffraction. Scripta Materialia, 54. (2006) 1901-1905. 